\title{
Early modification of sickle cell disease clinical course by UDP-glucuronosyltransferase 1A1 gene promoter polymorphism
}

\author{
Rute Martins · Anabela Morais · Alexandra Dias · Isabel Soares · Cristiana Rolão • \\ J. L. Ducla-Soares · Lígia Braga · Teresa Seixas · Baltazar Nunes · Gabriel Olim · \\ Luísa Romão · João Lavinha $\cdot$ Paula Faustino
}

Received: 23 January 2008/Accepted: 4 March 2008/Published online: 5 April 2008

(C) The Japan Society of Human Genetics and Springer 2008

\begin{abstract}
Elevated erythrocyte destruction in sickle cell disease (SCD) results in chronic hyperbilirubinaemia and, in a subset of patients, cholelithiasis occurs. We investigated whether the $(\mathrm{TA})_{\mathrm{n}}$ promoter polymorphism in the UDP-glucuronosyltransferase 1A1 gene (UGT1A1) may modify bilirubin metabolism, influencing bilirubinaemia, predisposition to cholelithiasis and subsequent cholecystectomy, in a group of 153 young SCD patients (mean age $12.0 \pm 9.0$ years) predominantly of Bantu beta $\mathrm{S}$ haplotype. The concomitant effect of alpha thalassaemia was also analysed. Among the several UGTIAl genotypes found, the most frequent were the $(\mathrm{TA})_{6} /(\mathrm{TA})_{6}(n=37),(\mathrm{TA})_{6} /(\mathrm{TA})_{7}$ $(n=60)$ and $(\mathrm{TA})_{7} /(\mathrm{TA})_{7}(n=29)$. These groups of patients did not significantly differ in age, gender ratio and haemoglobin, foetal haemoglobin and reticulocyte levels. On the other hand, total bilirubin levels were significantly
\end{abstract}

Electronic supplementary material The online version of this article (doi:10.1007/s10038-008-0281-3) contains supplementary material, which is available to authorised users.

R. Martins · L. Romão · J. Lavinha · P. Faustino $(\square)$

Centro de Genética Humana, Instituto Nacional

de Saúde Dr. Ricardo Jorge (INSA), Avenida Padre Cruz,

1649-016 Lisboa, Portugal

e-mail: paula.faustino@insa.min-saude.pt

A. Morais

Serviço de Pediatria, Hospital de Santa Maria (HSM),

Lisboa, Portugal

A. Dias

Serviço de Pediatria, Hospital Fernando Fonseca,

Amadora, Portugal

I. Soares

Serviço de Pediatria, Hospital Garcia de Orta,

Almada, Portugal different between groups, with an increased (TA) repeat number being associated with higher bilirubinaemia. Furthermore, both cholelithiasis and cholecystectomy were more frequent in groups with higher (TA) repeat number, although the former association was not statistically significant. None of the mentioned parameters is statistically different within UGT1A1 groups with the presence of alpha thalassaemia. Thus, the UGTIAl promoter polymorphism may represent an important nonglobin genetic modifier of Bantu SCD patients' clinical manifestations, even at a young age.

Keywords UGT1A1 - Sickle cell disease ·

Modifier genes $\cdot$ Hyperbilirubinaemia $\cdot$ Alpha thalassaemia

\section{Introduction}

Sickle cell disease (SCD; OMIM \#603903) is the most common genetic abnormality affecting people of African

\author{
C. Rolão · J. L. Ducla-Soares \\ Serviço de Medicina I-D, HSM, Lisboa, Portugal \\ L. Braga \\ Serviço 1, Medicina, Hospital Dona Estefânia, \\ Lisboa, Portugal \\ T. Seixas \\ Centro de Biopatologia, INSA, Lisboa, Portugal \\ B. Nunes \\ Observatório Nacional de Saúde, INSA, Lisboa, Portugal \\ G. Olim \\ Hospital da Força Aérea, Lisboa, Portugal
}


ancestry. It is caused by a molecular defect in the haemoglobin $(\mathrm{Hb})$ beta $(\beta)$-chain, where valine is substituted for glutamic acid in the sixth amino acid position. The resulting variant is called $\mathrm{Hb} \mathrm{S}$ as opposed to the normal adult $\mathrm{Hb} \mathrm{A}$. The polymerisation of deoxygenated $\mathrm{Hb} \mathrm{S}$ is the primary event in the molecular pathogenesis of SCD, resulting in a distortion of the red cell shape and a marked decrease in its deformability. SCD is characterised by a chronic haemolytic anaemia and recurrent vasoocclusive episodes, leading to multisystemic complications with a wide variation in severity (Serjeant 2001). Part of this clinical heterogeneity can be explained by the coinheritance of genetic modifiers linked or nonlinked to the globin gene clusters (Steinberg and Adewoye 2006).

It is known that the accelerated erythrocyte destruction in SCD often leads to chronic hyperbilirubinaemia, as bilirubin catabolism is the final step in the breakdown of haem from haemoglobin. Consequently, some clinical complications, such as cholelithiasis, recurrent painful abdominal events and cholecystitis are frequent in this pathology.

The primary bilirubin-catabolising hepatic enzyme, UDP-glucuronosyltransferase 1A1 (UGT1A1; Chr 2q37; EC 2.4.1.17), mediates the conjugation of bilirubin into a water-soluble conjugated form that is excreted in the bile. The UGT1A1 promoter contains an $\mathrm{A}(\mathrm{TA})_{\mathrm{n}} \mathrm{TAA}$ sequence with a common (TA) ${ }_{6}$ tandem repeat. The homozygosity for the $(\mathrm{TA})_{7}$ repeat has been associated with decreased enzyme function and Gilbert's syndrome of unconjugated hyperbilirubinaemia (Monaghan et al 1996). Other alleles, a shorter $(\mathrm{TA})_{5}$ and a longer $(\mathrm{TA})_{8}$, have been described in people of African descent (Beutler et al. 1998). Cholelithiasis, by promoting cholecystitis, is responsible for high levels of morbidity in SCD patients, and elective cholecystectomy is therefore recommended for patients developing this complication.

The aim of this study was to determine whether the promoter UGTIAl polymorphism (resulting in UGT1A1 activity variation) could modify bilirubin metabolism and affect serum bilirubin concentration in young SCD patients, thereby influencing the development of cholelithiasis and subsequently cholecystectomy. Also, the effect of alpha thalassaemia ( $\alpha$-thalassaemia) within UGTIAl genotype groups was investigated.

\section{Patients and methods}

This study was performed on 153 young Portuguese SCD patients (mean age 12.0 \pm 9.0 years), the majority descending from African immigrants (preponderantly from Angola, Sao Tome and Principe and Cape Verde). All patients, or their legal representatives, gave informed consent prior to their inclusion in the study. SCD steady-state patient data, concerning haemoglobin, foetal haemoglobin, reticulocytes and total bilirubin levels (determined by standard procedures) were averaged for each patient, and clinical information was gathered for cholelithiasis (detected by liver/biliary ultrasound scans) and cholecystectomy. Genomic DNA was extracted from peripheral blood leukocytes by a salting-out procedure (Miller et al 1988). The homozygosity for the SCD mutation was confirmed by a bidirectional allele-specific polymerase chain reaction (PCR) as described (Liu et al. 1997). The number of (TA) repeats in the UGTIAI promoter was analysed by a PCR-based methodology using the primers described by Monaghan et al. (1996) in which the sense primer was 5carboxyfluorescein (FAM) fluorescent-tagged. One aliquot of each PCR product was analysed by Gene Scan 3.7 software, along with a molecular weight marker.

Beta globin ( $\beta$-globin) gene-cluster haplotypes were assigned after examining nine restriction endonuclease sites within the cluster [Hinc II $(\varepsilon), X m n$ I $\left(5^{\prime}\right.$ to $\left.{ }^{\mathrm{G}} \gamma\right)$, Hind III (within ${ }^{\mathrm{G}} \gamma$ and ${ }^{\mathrm{A}} \gamma$ ), Hinc II (within and $3^{\prime}$ to $\psi \beta$ ), Hinf I ( $5^{\prime}$ to $\beta$ ), Ava II (within $\beta$ ), and Hinf I (3' to $\beta$ )]. Aliquots of the amplified products were digested with the appropriate restriction enzymes under the conditions recommended by the manufacturer. Haplotypes were established by determining the presence or absence of cleavage at each site and by compiling the results into one pattern classified according to Orkin et al. (1982). The allelic phase was determined by family studies whenever necessary. The $-\alpha^{3.7} \mathrm{~kb}$ deletion was searched for by gap PCR, as previously described (Dodé et al. 1992). Individuals were scored according to the presence/absence of deletional alleles. In order to perform statistical analyses, SCD patients presenting one or two deletional $\left(-\alpha^{3.7}\right)$ alleles were integrated in the same group, named $\alpha$-thal (see Table 3).

All statistical analyses were performed using the statistical software package SPSS 14.0. The significance of the differences between groups of patients was assessed using the Kruskal-Wallis, chi-square, analysis of variance (ANOVA), Wald, Mann-Whitney $U$ or Fisher's exact tests, as appropriate. The odds ratios (OR) were obtained by applying a logistic regression model using the UGTIAl genotype as the independent variable and the cholelithiasis and cholecystectomy as dependent variables. The reference class was the 6/6 UGTIAl genotype. Significance for statistical analysis was defined as a $P<0.05$.

\section{Results}

The homozygosity for the sickle cell mutation (HBB:c.20A > T) was confirmed in all patients. The 
UGT1A1 PCR fragments obtained ranged between 96 and $102 \mathrm{bp}$, which corresponded to a $(\mathrm{TA})_{5-8}$ variation. Consequently, several UGT1A1 genotypes were found: $5 / 5$ $(n=1) ; 5 / 6 \quad(n=9) ; 5 / 7 \quad(n=5) ; 5 / 8 \quad(n=3) ; 6 / 6$ $(n=37) ; 6 / 7(n=60) ; 6 / 8(n=6) ; 7 / 7(n=29)$ and $(7 /$ 8) $(n=3)$; (Appendix 1 of Supplementary Material). Only patients belonging to the three largest genotype groups (namely, 6/6, 6/7 and 7/7) were considered for statistical analyses. Comparisons performed for these three groups of patients did not reveal any significant difference concerning age, gender ratio, and $\mathrm{Hb}, \mathrm{Hb} \mathrm{F}$ and reticulocyte levels, which denotes a similar degree of haemolysis between groups. However, total bilirubin levels were significantly different between groups ( $P=0.003$; Kruskal-Wallis test), with an increased (TA) repeat number being associated with higher bilirubinaemia (Table 1).

The chi-square tests used for cholelithiasis and cholecystectomy data showed that both cholelithiasis $(P=$ $0.407)$ and cholecystectomy $(P=0.016)$ were increased in the patients with higher (TA) repeat number, although the former difference was not statistically significant (Table 1). The OR of having cholelithiasis for genotypes $6 / 7[\mathrm{OR}=1.500 ; 95 \%$ confidence interval $(\mathrm{CI})=0.595-$ $3.784)$ and $7 / 7(\mathrm{OR}=2.057 ; 95 \% \mathrm{CI}=0.708-5.980]$ was increased when compared with 6/6. The same comparison for cholecystectomy revealed an increased risk only for

Table 1 Comparison of sickle cell disease phenotype features in patients stratified according to UGT1A1 genotype

\begin{tabular}{llll}
\hline & \multicolumn{3}{l}{ UGT1A1 genotype } \\
\cline { 2 - 4 } & $6 / 6$ & $6 / 7$ & $7 / 7$ \\
\hline Number & 37 & 60 & 29 \\
Age (years) & $12.9 \pm 8.6$ & $9.0 \pm 7.4$ & $12.7 \pm 9.0$ \\
$P^{*}$ & 0.580 & & \\
Gender ratio (M/F) & $18 / 19$ & $30 / 30$ & $14 / 15$ \\
$P^{* *}$ & 0.985 & & \\
Haemoglobin (g/dl) & $7.88 \pm 0.92$ & $7.93 \pm 1.37$ & $8.40 \pm 1.11$ \\
$P^{* * *}$ & 0.398 & & \\
Haemoglobin $\mathrm{F}(\%)$ & $8.33 \pm 5.27$ & $10.03 \pm 6.39$ & $8.46 \pm 5.19$ \\
$P^{*}$ & 0.535 & & \\
Reticulocytes (\%) & $10.21 \pm 3.98$ & $11.61 \pm 6.93$ & $11.70 \pm 4.58$ \\
$P^{*}$ & 0.500 & & \\
Total bilirubin (mg/dl) & $2.55 \pm 1.78$ & $3.20 \pm 3.14$ & $4.67 \pm 3.67$ \\
$P^{*}$ & 0.003 & & \\
Cholelithiasis (\%) & 29.4 & 38.5 & 46.2 \\
$P^{* *}$ & 0.407 & & \\
Cholecystectomy (\%) & 5.7 & 3.8 & \\
$P^{* *}$ & 0.016 & & \\
\hline
\end{tabular}

* Kruskal-Wallis test

** Chi-square test

*** Analysis of variance test genotype $7 / 7 \quad(\mathrm{OR}=4.714 ; 95 \% \quad \mathrm{CI}=0.869-25.581)$ (Table 2).

To gain further insight into the modifying effect of UGT1A1 polymorphism, the $\beta$ S haplotype and the $\alpha$-globin genotype were determined in our SCD patients. The prevalence of the Bantu haplotype was similar among the three UGT1A1 groups (Bantu allelic frequency in the $6 / 6$ UGT1A1 group was $73.0 \%$; in the $6 / 7$ group $62.3 \%$; and in the $7 / 7$ group $67.2 \% ; P=0.305)$. The overall $\alpha$-thalassaemia $\left(-\alpha^{3.7}\right)$ allelic frequency was $26 \%$ and was not significantly different between UGT1Al genotype groups. We found that in young SCD patients predominantly of Bantu $\beta \mathrm{S}$ haplotype, the coinheritance of $\alpha$-thalassaemia did not significantly influence the level, total bilirubin level, cholelithogenesis and the need for cholecystectomy (Table 3).

Phenotype features of patients belonging to the less frequent genotype groups are summarised in Appendix 1 of Supplementary Material.

\section{Discussion}

In this study, we investigated the genetic architecture of a young population with a SCD subphenotype characterised by hyperbilirubinaemia and cholelithiasis. The (TA) repeat number found within the UGT1Al gene promoter varied between 5 and 8, which was expected due to the African ancestry of this population (Beutler et al. 1998).

The coinheritance of Gilbert's syndrome determinant and genetic alterations associated with disorders that increase turnover of red blood cells or their precursors has been reported to elevate bilirubin levels, e.g. in $\beta$-thalassaemia (Galanello et al. 1997, 1999b), G6PD deficiency (Galanello et al. 1999a) and SCD (Adekile et al. 2005; Chaar et al. 2005; Fertrin et al. 2003; Harverfield et al. 2005; Passon et al. 2001). In fact, in addition to the results presented here, the mentioned studies performed in SCD

Table 2 Calculation of odds ratios between UGT1A1 genotype groups

\begin{tabular}{lll}
\hline UGT1A1 genotype & \multicolumn{2}{l}{ Odds ratios } \\
\cline { 2 - 3 } & $6 / 6-6 / 7$ & $6 / 6-7 / 7$ \\
\hline Cholelithiasis & 1.500 & 2.057 \\
$95 \%$ CI & $0.595-3.784$ & $0.708-5.980$ \\
$P^{*}$ & 0.390 & 0.185 \\
Cholecystectomy & 0.647 & 4.714 \\
$95 \%$ CI & $0.087-4.821$ & $0.869-25.581$ \\
$P^{*}$ & 0.671 & 0.072 \\
\hline$C I$ confidence interval & & \\
$*$ Wald test & &
\end{tabular}


Table 3 Influence of $\alpha$ thalassaemia ( $\alpha$-thal.) on bilirubin-associated parameters among UGT1A1 genotype groups

\begin{tabular}{lllll}
\hline & & \multicolumn{4}{l}{ UGT1Al genotype groups } \\
\cline { 2 - 4 } & & $6 / 6$ & $6 / 7$ & $7 / 7$ \\
\hline Number & $\alpha \alpha / \alpha \alpha$ & 19 & 36 & 14 \\
& $\alpha$-thal. & 18 & 24 & 15 \\
Haemoglobin (g/dl) & $\alpha \alpha / \alpha \alpha$ & $7.59 \pm 0.87$ & $8.09 \pm 1.46$ & $7.70 \pm 0.84$ \\
& $\alpha$-thal. & $8.14 \pm 1.08$ & $7.87 \pm 0.93$ & $8.35 \pm 1.05$ \\
$P^{*}$ & & 0.192 & 0.389 & 0.155 \\
Total bilirubin (mg/dl) & $\alpha \alpha / \alpha \alpha$ & $2.80 \pm 2.45$ & $3.61 \pm 3.75$ & $5.42 \pm 4.94$ \\
& $\alpha$-thal. & $2.79 \pm 2.41$ & $2.51 \pm 1.53$ & $3.98 \pm 1.84$ \\
$P^{*}$ & & 0.961 & 0.205 & 0.793 \\
Cholelithiasis $(\%)$ & $\alpha \alpha / \alpha \alpha$ & 29.4 & 41.2 & 58.3 \\
& $\alpha$-thal. & 29.4 & 36.8 & 35.7 \\
$P^{* *}$ & & 1.000 & 1.000 & 0.431 \\
Cholecystectomy (\%) & $\alpha \alpha / \alpha \alpha$ & 11.8 & 5.7 & 30.8 \\
& $\alpha$-thal. & 0.00 & 0.00 & 14.3 \\
$P^{* *}$ & & 0.229 & 0.535 & 0.385 \\
\hline
\end{tabular}

* Mann-Whitney test

** Fisher's exact test that the frequency of cholelithiasis was significantly higher in an SCD group of children having $7 / 7$ or $7 / 8$ genotype. On the whole, analysing our results along with previously published data, we can conclude that the UGT1A1 promoter genotype is unquestionably an important genetic determinant of hyperbilirubinaemia in SCD. However, its influence on cholelithiasis development is not so straightforward and seems to be modulated by other factors, among which age is relevant. Concerning patients who need cholecystectomy, their inclusion in the $7 / 7$ genotype group is remarkable, thereby confirming the penetrance of this genotype.

It is known that the coinheritance of $\alpha$-thalassaemia and SCD determinants reduces the mean corpuscular haemoglobin concentration of red blood cells, which tends to inhibit sickling. It was observed that the coexistence of $\alpha$ thalassaemia decreases the chance of developing gallstones in Arab Indian haplotype SCD patients, which may be related to lower haemolysis, as suggested by their predisposition to present, in general, higher mean $\mathrm{Hb}$ levels (Haider et al. 1998). In addition, Adekile et al. (2005) observed that the $\beta$-globin haplotype and the coexisting $\alpha$ thalassaemia did not have significant influence on serum bilirubin levels in Arab Indian haplotype SCD patients (Adekile et al. 2005). Furthermore, Chaar et al. (2006) showed that although $\alpha$-thalassaemia is associated with a modest reduction in haemolysis and unconjugated bilirubin level, UGT1A1 polymorphism outweighs its effect on cholelithogenesis in SCD patients predominantly of Benim $\beta$ S haplotype (Chaar et al. 2006). Vasavda et al. (2007) also observed that $\alpha$-thalassaemia was significantly associated with reduced bilirubin levels in SCD adult patients. In our young SCD patient series predominantly of Bantu $\beta \mathrm{S}$ haplotype, we found that the coinheritance of (Passon et al. 2001). Finally, Chaar et al. (2005) observed 
$\alpha$-thalassaemia does not significantly influence $\mathrm{Hb}$ level, total bilirubin level, cholelithogenesis and the need for cholecystectomy (Table 3). However, we observed that the coinheritance of $\alpha$-thalassaemia is slightly associated with a positive effect on the mentioned parameters, mainly in the $7 / 7$ genotype group in which patients presented higher haemoglobin level, lower bilirubin, fewer cholelithiasis and undergo cholecystectomy less frequently.

In conclusion, our study, the first performed regarding young Bantu SCD patients, reinforces the concept that the sickle cell mutation alone is not sufficient to explain the wide range of phenotypic expression characteristic of SCD. Our results attribute to UGTIAl promoter polymorphism an important modifying effect of the clinical manifestations in Bantu SCD patients, namely, in bilirubin metabolism, cholelithiasis development and the need for cholecystectomy, even at a young age. Also, we observed that in these patients, the modulating effect of the UGTIAl promoter polymorphism is not significantly altered by the coinheritance of $\alpha$-thalassaemia determinants.

Acknowledgments We thank the "Unidade Laboratorial de Utilização Comum" of the National Institute of Health Dr. Ricardo Jorge for technical support. This work was partially supported by FCT grant IME/MGI/49853/2003, "Programa de Financiamento Plurianual do CIGMH" and "Programa Operacional Saúde - Saúde XXI". The experiments performed in our research work comply with the current Portuguese applicable laws. This work obtained the approval of the local ethics committee.

\section{References}

Adekile A, Kutlar F, McKie A, Addington A, Elam D, Holley L, Clair B, Kutlar A (2005) The influence of uridine diphosphate glucuronyl transferase $1 \mathrm{~A}$ promoter polymorphisms, $\beta$ S-globin trait and $\mathrm{HbF}$ on steady-state bilirubin levels in sickle cell anemia. Eur J Haematol 75:150-155

Beutler E, Gelbart T, Demina A (1998) Racial variability in the UDPglucuronosyltransferase 1 (UGT1A1) promoter: a balanced polymorphism for regulation of bilirubin metabolism? Proc Natl Acad Sci USA 95:8170-8174

Chaar V, Kéclard L, Diara JP, Leturdu C, Elion J, Krishnamoorthy R, Clayton J, Romana M (2005) Association of UGT1A1 polymorphism with prevalence and age at onset of cholelithiasis in sickle cell anemia. Haematologica 90:188-193

Chaar V, Keclard L, Etienne-Julan M, Diara JP, Elion J, Krishnamoorthy R, Romana M (2006) UGT1A1 polymorphism outweighs the modest effect of deletional $(-3.7 \mathrm{~kb})$ alphathalassemia on cholelithogenesis in sickle cell anemia. Am J Hematol 81:377-379
Dodé C, Krishnamoorthy R, Lamb J, Rochette J (1992) Rapid analysis of $\alpha^{3.7}$ thalassaemia and $\alpha \alpha \alpha^{\text {anti3.7 }}$ triplication by enzymatic amplification analysis. Br J Haematol 83:105-111

Fertrin KY, Melo MB, Assis AM, Saad STO, Costa FF (2003) UDPglucuronosyltransferase 1 gene promoter polymorphism is associated with increased serum bilirubin levels and cholecystectomy in patients with sickle cell anemia. Clin Genet 64:160 162

Galanello R, Perseu L, Melis M, Cipollina L, Barella S, Giagu N (1997) Hyperbilirubinaemia in heterozygous beta-thalassaemia is related to co-inherited Gilbert's syndrome. $\mathrm{Br} \mathrm{J}$ Haematol 99:433-436

Galanello R, Cipollina M, Carboni G, Perseu L, Barella S, Corrias A, Cao A (1999a) Hyperbilirubinemia, glucose-6-phosphate dehydrogenase deficiency and Gilbert's syndrome. Eur J Pediatr 158:914-916

Galanello R, Cipollina M, Dessi C, Giaqu N, Lai E, Cao A (1999b) Co-inherited Gilbert's syndrome: a factor determining hyperbilirubinemia in homozygous beta-thalassemia. Haematologica 84:103-105

Haider MZ, Ashebu S, Aduh P, Adekile AD (1998) Influence of alpha-thalassemia on cholelithiasis in SS patients with elevated $\mathrm{Hb}$ F. Acta Haematol 100:147-150

Harverfield EV, McKenzie CA, Forrester T, Bouzekri N, Harding R, Serjeant G, Walker T, Peto TEA, Ward R, Weatherall DJ (2005) UGT1A1 variation and gallstone formation in sickle cell disease. Blood 105:968-972

Liu Q, Thorland EC, Heit JA, Sommer SS (1997) Overlapping PCR for bidirectional PCR amplification of specific alleles: a rapid one-tube method for simultaneously differentiating homozygotes and heterozygotes. Genome Res 7:389-398

Miller SA, Dykes DD, Polesky HF (1988) A simple salting-out procedure for extracting DNA from human nucleated cells. Nucleic Acids Res 16:1215

Monaghan G, Ryan M, Seddon R, Hume R, Burchell B (1996) Genetic variation in bilirubin UDP-glucuronosyltransferase gene promoter and Gilbert's syndrome. Lancet 347:578-581

Orkin SH, Kazazian HH, Antonarakis SE, Goff SC, Boeham CD, Sexton JP, Waber PG, Giardina PJ (1982) Linkage of $\beta$ thalassaemia mutations and $\beta$-globin gene polymorphisms with DNA polymorphism in human $\beta$-globin gene cluster. Nature 296:627-631

Passon RG, Howard TA, Zimmerman SA, Schultz WH, Ware RE (2001) Influence of Bilirubin Uridine Diphosphate-Glucuronosyltransferase 1A promoter polymorphisms on serum bilirubin levels and cholelithiasis in children with sickle cell anemia. J Pediatr Hematol Oncol 23:448-451

Serjeant GR (2001) The emerging understanding of sickle cell disease. Br J Haematol 112:3-18

Steinberg MH, Adewoye AH (2006) Modifier genes and sickle cell anaemia. Curr Opin Hematol 13:131-136

Vasavda N, Menzel S, Kondaveeti S, Maytham E, Awogbade M, Bannister S, Cunningham J, Eichholz A, Daniel Y, Okpala I, Fulford T, Thein SW (2007) The linear effects of $\alpha$-thalassaemia, the UGT1A1 and HMOX1 polymorphisms on cholelithiasis in sickle cell disease. Br J Haematol 138:263-270 